\title{
Socio-economic and demographic factors associated with fertility preferences among women of reproductive age in Ghana: evidence from the 2014 Demographic and Health Survey
}

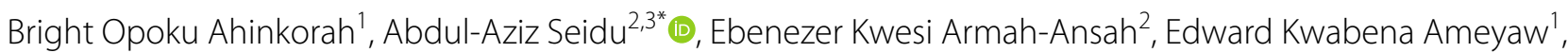
Eugene Budu ${ }^{2}$ and Sanni Yaya ${ }^{4,5}$

\begin{abstract}
Background: Understanding women's desire to have more children is critical for planning towards future reproductive health behaviour. We examined the association between socio-economic and demographic factors and fertility preferences among women of reproductive age in Ghana.

Methods: This study used data from the 2014 Ghana Demographic and Health Survey. The sample consisted of 5389 women of reproductive age. We fitted Binary logistic regression models to assess the association between socio-economic status and fertility preferences, whiles controlling for demographic factors. The results were presented as crude odds ratios (CORs) and adjusted odds ratios (aORs) together with their corresponding 95\% confidence intervals.

Results: Approximately $60 \%$ of women of reproductive age in Ghana desired for more children. Women with no formal education were more likely to desire for more children compared to those with higher level of education $(\mathrm{aOR}=2.16,95 \% \mathrm{Cl} 1.29-3.48)$. The odds of desire for more children was higher among women who lived in rural areas compared to those who lived in urban areas $(\mathrm{aOR}=1.24,95 \% \mathrm{Cl} 1.01-1.53)$. With region, women who lived in the Northern region were more likely to desire for more children compared to those who lived in the Ashanti region ( $\mathrm{aOR}=4.03,95 \% \mathrm{Cl}$ 2.69-6.04). Similarly, women who belonged to other ethnic groups were more likely to desire for more children compared to Akans $(\mathrm{aOR}=1.78,95 \% \mathrm{Cl} 1.35-2.35)$. The desire for more children was higher among women with 0-3 births compared to those with four or more births ( $\mathrm{aOR}=7.15,95 \% \mathrm{Cl}$ 5.97-8.58). In terms of religion, Muslim women were more likely to desire for more children compared to Christians $(\mathrm{aOR}=1.87,95 \% \mathrm{Cl}$ 1.49-2.34).
\end{abstract}

Conclusion: This study concludes that women in high-socio economic status are less likely to desire more children. On the other hand, women in the Northern, Upper East and those belonging to the Islamic religious sect tend to desire more children. To aid in fertility control programmes designing and strengthening of existing ones, these factors ought to be critically considered.

*Correspondence: abdul-aziz.seidu@stu.ucc.edu.gh

${ }^{2}$ Department of Population and Health, University of Cape Coast, Cape Coast, Ghana

Full list of author information is available at the end of the article

(c) The Author(s) 2021. Open Access This article is licensed under a Creative Commons Attribution 4.0 International License, which permits use, sharing, adaptation, distribution and reproduction in any medium or format, as long as you give appropriate credit to the original author(s) and the source, provide a link to the Creative Commons licence, and indicate if changes were made. The images or other third party material in this article are included in the article's Creative Commons licence, unless indicated otherwise in a credit line to the material. If material is not included in the article's Creative Commons licence and your intended use is not permitted by statutory regulation or exceeds the permitted use, you will need to obtain permission directly from the copyright holder. To view a copy of this licence, visit http://creativecommons.org/licenses/by/4.0/. The Creative Commons Public Domain Dedication waiver (http://creativeco mmons.org/publicdomain/zero/1.0/) applies to the data made available in this article, unless otherwise stated in a credit line to the data. 
Keywords: Fertility, Preferences, Ghana, Desire for children, Women, DHS

\section{Plain English summary}

Understanding women's desire to have more children is critical for planning towards future reproductive health behaviour. We examined the association between socioeconomic and demographic factors and fertility preferences among women of reproductive age in Ghana.

This study used data from the 2014 Ghana Demographic and Health Survey. The women who participated in the study were 5389 and aged 15-49. We calculated the distribution of the socio-economic and demographic factors across fertility preferences using percentages. Next, we carried out a bivariate logistic regression analysis to examine the independent associations between the socio-economic and demographic variables and desire for more children. The results were presented using crude odds ratios. Finally, we fitted a multivariable logistic regression model to examine the socio-economic and demographic factors associated with desire for more children. The results were presented as adjusted odds ratios. Statistical significance was determined using 95\% confidence intervals. The results show that women belonging to the poorest wealth quintile and those with no formal education were more likely to desire for more children compared to richest and women with higher education respectively. Desire for more children was less likely among women aged 45-49 compared to those aged 15-19. With region of residence, women who lived in the Northern region were more likely to desire for more children compared to those who lived in the Greater Accra region. Similarly, women who belonged to other ethnic groups were more likely to desire for more children compared to Akans. The desire for more children increased with lower parity as women with $0-3$ births were more likely to desire for more children. This study concludes that women in high-socio economic status are less likely to desire more children. On the other hand, women in the Northern, Upper East and those belonging to the Islamic religious sect tend to desire more children. To aid in fertility control programmes designing and strengthening of existing ones, these factors ought to be critically considered.

\section{Background}

The size of a family is of great importance not only for a country but for the welfare and health of the individual, family and community [1]. The current demographic changes have witnessed unprecedented reduction in the level of fertility in all regions of the world [2]. This is relevant in low- and middle-income countries where population growth has adverse effects on poverty situation and wellbeing of the nations [3]. Fertility is the major determinant of high population growth and on a larger scale, population growth could hinder a country's economic performance as this may put pressure on the already limited infrastructure and government funds $[4$, 5].

Many households with smaller family sizes are more likely to benefit from demographic dividends and this suggests that uncontrolled population growth will have some dire consequences on the economic status as well as other devastating effects on maternal and child health $[4,6]$. High fertility coupled with high population growth may lead to increase in maternal and paediatric diseases and or mortality [7]. Attempts to control fertility or child birth have over the years focused on meeting contraceptive needs of the population and improving public health education on the knowledge, awareness and proper use of contraceptives [8]. Contraceptive use has helped to prevent about 2.7 million infant and maternal mortality globally [9].

The desire to have more children is important for understanding future reproductive behaviour [10]. In Ghana, the decrease in fertility from 6.4 in 1988 to 4.2 in 2014 may be due to government policies initiated to manage population growth [10]. Such policies include the Contraceptive Social Marketing (CSM) project (1987-1990), the Ghana Family Planning and Health Programme (FPHP) (1990-1996), the Ghana Population and AIDS Project (GHANAPA) (1996-2000) and 1994 and 2004 Ghana Population Policies [8].

Fertility preference is pivotal in the fertility tendencies and this is also influenced by numerous interrelated variables such as age, marital status, income, educational level and parity [11-13]. Socio-economic status, education, maternal age, number of children ever born, infant mortality, and opinion of key people about the number of children to bear have been identified to have significant influence on fertility preferences [14-17]. The 2014 Ghana Demographic and Health Survey (GDHS) indicates that women with secondary or higher education (28\%) are less likely to want more children as compared with their counterparts with no formal education or with primary education [10].

In Ghana, socio-economic status and fertility preference influence reproductive health and behaviour of both men and women in their reproductive ages significantly [18]. A phenomenon that has received minimal attention in Ghana is the association between socio-economic 
status and fertility preferences among women of reproductive age. While several studies have been carried out on childhood mortality, intra-household bargaining power and fertility preferences among women in Ghana $[3,19,20]$, to the best of our knowledge, very little evidence exist on the association between socio-economic status and fertility preferences among women of reproductive age in Ghana. Hence, in this study, we sought to examine the association between socio-economic and fertility preferences among women of reproductive age in Ghana, while controlling for relevant demographic factors. Findings from such a nationally representative study will be vital to aid in strengthening existing measures to tackle high fertility and improvement in maternal and child health.

\section{Methodology}

\section{Data source}

Data for this study was obtained from the 2014 Ghana Demographic and Health Survey (GDHS) [10]. This is a cross sectional study implemented by the Ghana Statistical Service (GSS), Ghana Health Service (GHS), and the National Public Health Reference Laboratory (NPHRL). Whilst the Inner City Fund (ICF) provided technical assistance, about nine organisations financed the study including the United States Agency for International Development (USAID), the United Nations Development Programme (UNDP) and the Ghana AIDS Commission (GAC). The 2014 GDHS offers an updated estimate of fundamental demographic and health information covered by the early surveys since its inception in 1988. The survey targeted women aged 15-49 and men aged 15-59. The sampling procedure follows a two-stage cluster sampling approach. Selection of sample points or clusters was done in the first stage. This yielded 427 clusters from rural (211) and urban (216) locations. Systematic sampling of households occurred in the second stage through random sampling approach. Detailed description of the sampling procedure and other methodological issues are extensively espoused in the report [10]. Weighting factors were added to the data files to ensure that computed results will be proportional at the national level. This was needful as the sample was not self-weighting at the national level. The sample for our study consisted of 5389 women of reproductive age who were married/cohabiting or had previously married.

\section{Derivation of study variables Outcome variable}

The outcome variable for the study is fertility preferences. This was derived from a question answered by women aged 15-49 during the 2014 GDHS. The question was framed as "would you like to have a (another) child with your husband/partner, or would you prefer not to have any more children with him?" Responses to this question was categorised into: "want a (another) child," "want no more," "cannot get pregnant," "undecided," and "don't know." Our outcome variable was computed from two of these responses namely "want a (another) child," coded as 1 and "want no more," coded as 0 . Women who provided "undecided," and "don't know" responses were excluded because their responses were unclear about their fertility preference and those who indicated "cannot get pregnant were not at risk of getting pregnant. These reasons necessitated the decision to drop them from our sample in other not to get biased estimates.

\section{Explanatory variable}

Socio-economic status is the cardinal explanatory variable for the study. Education and wealth status were used as proxies for socio-economic status. Whilst varied indicators are used for measuring socio-economic status, these two indicators (education and wealth) have dominated in the literature over time [21-23]. Education as used in the DHS, focuses on highest level of education that a person has completed. We used education of both the women and their partners. This is categorised into no education, primary, secondary and higher. Wealth quintile on the order hand, is measured as an ordinal variable ranging from poorest to richest. It is a composite measure that is computed by identification of household assets such as bicycle and television. Through Principal Component Analysis (PCA), these assets are transformed into an index and categorised into poorest, poorer, middle, richer and richest [24]. We also considered some critical socio-demographic characteristics of the sampled women. These are age, residence, occupation, region, ethnicity, parity, religion and access to mass media (newspaper/magazine, radio and television) (see Table 1).

\section{Data analyses}

Data for this study were analysed using Stata 14.2 for Windows. First, we calculated the distribution of the socio-economic and demographic factors across fertility preferences using percentages (see Table 1). After this, we checked for multicollinearity among the explanatory variables, using the variance inflation factor (VIF) and the results showed no evidence of high collinearity (Mean VIF $=1.72$, maximum $\mathrm{VIF}=3.47$, and minimum $\mathrm{VIF}=1.10$ ). Next, we carried out a bivariate logistic regression analysis to examine the independent associations between the socio-economic and demographic variables and desire for more children. The results were presented using crude odds ratios (cOR). Finally, we fitted a multivariable logistic regression model to examine the socio-economic and demographic predictors 
Table 1 Fertility preferences across women's socio-economic status and their demographic characteristics. Source: Computed from 2014 GDHS

\begin{tabular}{|c|c|c|c|c|}
\hline \multirow[t]{2}{*}{ Variables } & \multirow[t]{2}{*}{ Weighted N } & \multirow[t]{2}{*}{ Weighted \% } & \multicolumn{2}{|l|}{ Fertility preferences } \\
\hline & & & Want no more (40.3\%) & $\begin{array}{l}\text { Want } \\
\text { a (another) } \\
\text { child }(59.7 \%)\end{array}$ \\
\hline \multicolumn{5}{|c|}{ Socio-economic variables } \\
\hline \multicolumn{5}{|l|}{ Wealth quintile } \\
\hline Poorest & 1001 & 18.6 & 35.3 & 64.7 \\
\hline Poorer & 961 & 17.8 & 52.6 & 47.4 \\
\hline Middle & 1080 & 20.0 & 45.6 & 54.4 \\
\hline Richer & 1110 & 20.6 & 40.1 & 59.9 \\
\hline Richest & 1238 & 23.0 & 37.1 & 62.9 \\
\hline \multicolumn{5}{|c|}{ Level of education } \\
\hline No education & 1429 & 26.5 & 42.6 & 57.4 \\
\hline Primary & 980 & 18.2 & 48.0 & 52.0 \\
\hline Secondary & 2697 & 50.1 & 39.7 & 60.3 \\
\hline Higher & 283 & 5.3 & 37.0 & 63.0 \\
\hline \multicolumn{5}{|c|}{ Partner's level of education } \\
\hline No education & 1094 & 20.3 & 38.4 & 60.6 \\
\hline Primary & 473 & 8.8 & 41.7 & 58.3 \\
\hline Secondary & 3181 & 59.0 & 44.3 & 55.7 \\
\hline Higher & 640 & 11.9 & 33.8 & 66.2 \\
\hline \multicolumn{5}{|c|}{ Demographic variables } \\
\hline \multicolumn{5}{|l|}{ Age } \\
\hline $15-19$ & 105 & 2.0 & 5.8 & 94.2 \\
\hline $20-24$ & 621 & 11.5 & 9.1 & 90.9 \\
\hline $25-29$ & 1074 & 19.9 & 17.5 & 82.5 \\
\hline $30-34$ & 1105 & 20.5 & 34.3 & 65.7 \\
\hline $35-39$ & 1028 & 19.1 & 50.5 & 49.5 \\
\hline $40-44$ & 810 & 15.0 & 72.2 & 27.8 \\
\hline $45-49$ & 646 & 12.0 & 80.9 & 19.1 \\
\hline \multicolumn{5}{|l|}{ Residence } \\
\hline Urban & 2747 & 51.0 & 41.0 & 59.0 \\
\hline Rural & 2642 & 49.0 & 42.8 & 57.2 \\
\hline \multicolumn{5}{|l|}{ Occupation } \\
\hline Not working & 663 & 12.3 & 32.7 & 67.3 \\
\hline Managerial & 370 & 6.9 & 29.9 & 70.1 \\
\hline Clerical & 48 & 0.9 & 38.3 & 61.7 \\
\hline Sales & 2246 & 41.7 & 43.3 & 56.7 \\
\hline Agricultural & 1320 & 24.5 & 48.6 & 51.4 \\
\hline Household & 27 & 0.5 & 36.7 & 63.3 \\
\hline Manual & 715 & 13.3 & 39.9 & 60.1 \\
\hline \multicolumn{5}{|l|}{ Region } \\
\hline Western & 536 & 9.9 & 45.2 & 54.8 \\
\hline Central & 552 & 10.24 & 48.0 & 52.0 \\
\hline Greater Accra & 1045 & 19.4 & 42.4 & 57.6 \\
\hline Volta & 431 & 8.0 & 52.9 & 47.1 \\
\hline Eastern & 527 & 9.8 & 50.7 & 49.3 \\
\hline Ashanti & 972 & 18.0 & 43.7 & 56.3 \\
\hline Brong Ahafo & 418 & 7.8 & 40.1 & 59.9 \\
\hline Northern & 554 & 10.3 & 21.2 & 78.9 \\
\hline
\end{tabular}


Table 1 (continued)

\begin{tabular}{|c|c|c|c|c|}
\hline \multirow[t]{2}{*}{ Variables } & \multirow[t]{2}{*}{ Weighted N } & \multirow[t]{2}{*}{ Weighted \% } & \multicolumn{2}{|l|}{ Fertility preferences } \\
\hline & & & Want no more (40.3\%) & $\begin{array}{l}\text { Want } \\
\text { a (another) } \\
\text { child }(59.7 \%)\end{array}$ \\
\hline Upper East & 223 & 4.1 & 33.0 & 67.0 \\
\hline Upper West & 133 & 2.5 & 33.7 & 66.3 \\
\hline \multicolumn{5}{|l|}{ Ethnicity } \\
\hline Akan & 2591 & 48.1 & 47.4 & 52.7 \\
\hline Ga-Adangbe/Ewe & 1142 & 21.2 & 51.0 & 49.0 \\
\hline Mole-Dagbani & 849 & 15.8 & 31.3 & 68.7 \\
\hline Others & 807 & 15.0 & 28.5 & 71.5 \\
\hline \multicolumn{5}{|l|}{ Parity } \\
\hline $0-3$ births & 3147 & 58.4 & 21.0 & 79.0 \\
\hline Four or more births & 2242 & 41.6 & 71.1 & 28.9 \\
\hline \multicolumn{5}{|l|}{ Religion } \\
\hline Christianity & 4225 & 78.4 & 43.9 & 56.1 \\
\hline Islam & 862 & 16.0 & 26.5 & 73.5 \\
\hline Traditionalist & 141 & 2.6 & 41.0 & 59.0 \\
\hline No religion & 161 & 3.0 & 42.6 & 57.4 \\
\hline \multicolumn{5}{|c|}{ Frequency of reading newspaper/magazine } \\
\hline Not at all & 4694 & 87.1 & 42.7 & 57.3 \\
\hline Less than a week & 359 & 6.7 & 38.4 & 61.6 \\
\hline At least once a week & 336 & 6.2 & 33.9 & 66.1 \\
\hline \multicolumn{5}{|c|}{ Frequency of listening to radio } \\
\hline Not at all & 837 & 15.5 & 43.0 & 57.0 \\
\hline Less than once a week & 1744 & 32.4 & 43.1 & 56.9 \\
\hline At least once a week & 2808 & 52.1 & 40.7 & 59.3 \\
\hline \multicolumn{5}{|c|}{ Frequency of watching television } \\
\hline Not at all & 1421 & 26.4 & 48.4 & 51.6 \\
\hline Less than once a week & 1352 & 25.1 & 40.0 & 60.0 \\
\hline At least once a week & 2616 & 49.6 & 39.2 & 60.8 \\
\hline
\end{tabular}

of desire for more children. The results were presented as adjusted odds ratio (aORs) together with their corresponding 95\% confidence intervals signifying level of precision. On the account that the sample was not selfweighting, we applied sample weight in our computations whilst the survey (svy) command was used to cater for the study design.

\section{Ethical consideration}

The survey was ethically approved by the ICF International and Ethical Review Committee of Ghana Health Service [10]. We did not need ethical permission for this study since the DHS datasets are publicly accessible. All ethical procedures were, however, observed during to survey to align the study with the regulations for the protection of human rights as required by the U.S. Department of Health and Human Services. More details regarding DHS data and ethical standards are available at: http://goo.gl/ny8T6X.

\section{Results}

Table 1 presents results on fertility preferences across women's socio-economic status and their demographic characteristics. Approximately $60 \%$ of women of reproductive age in Ghana desired for more children. We found that the desire for more children was high among poorest women (64.4\%), women with higher level of education (63.0\%), those whose partners had higher level of education (66.2\%), women aged 15-19 (94.2\%), urban residents $(59.0 \%)$, women in managerial jobs (70.1\%) and women in the Northern region (78.9\%). Similar observation was made among women who belonged to other ethnic groups (71.5\%), those with parity 0-3 (79.0\%), Muslims (73.5\%), those who read newspaper/magazine at 
Table 2 Socio-economic and demographic factors associated with fertility preferences among women of reproductive age in Ghana. Source: Computed from 2014 GDHS

\begin{tabular}{|c|c|c|}
\hline Variables & $\begin{array}{l}\text { Model } 1 \\
\text { cOR } 95 \% \mathrm{Cl}\end{array}$ & $\begin{array}{l}\text { Model } 2 \\
\text { aOR } 95 \% \mathrm{Cl}\end{array}$ \\
\hline \multicolumn{3}{|l|}{ Wealth quintile } \\
\hline Poorest & $1.06[0.89-1.26]$ & $1.02[0.67-1.56]$ \\
\hline Poorer & $0.62^{* * *}[0.51-0.74]$ & $0.85[0.60-1.21]$ \\
\hline Middle & $0.73^{* *}[0.61-0.88]$ & $0.82[0.61-1.11]$ \\
\hline Richer & $0.97[0.80-1.17]$ & $0.91[0.70-1.17]$ \\
\hline Richest & Ref & Ref \\
\hline \multicolumn{3}{|c|}{ Level of education } \\
\hline No education & $0.64^{* *}[0.48-0.86]$ & $2.16^{* *}[1.29-3.48]$ \\
\hline Primary & $0.59^{* *}[0.44-0.80]$ & $1.90^{* *}[1.17-3.09]$ \\
\hline Secondary & $0.72^{*}[0.54-0.95]$ & $1.80^{* *}[1.17-2.78]$ \\
\hline Higher & Ref & Ref \\
\hline \multicolumn{3}{|c|}{ Partner's level of education } \\
\hline No education & $0.73^{* *}[0.60-0.90]$ & $0.80[0.57-1.13]$ \\
\hline Primary & $0.75^{*}[0.59-0.96]$ & $0.93[0.64-1.35]$ \\
\hline Secondary & $0.61^{* * *}[0.51-0.74]$ & $0.77[0.59-1.02]$ \\
\hline Higher & Ref & Ref \\
\hline \multicolumn{3}{|l|}{ Age } \\
\hline $15-19$ & Ref & Ref \\
\hline $20-24$ & $0.66[0.29-1.49]$ & $0.67[0.30-1.53]$ \\
\hline $25-29$ & $0.38^{*}[0.17-0.83]$ & $0.52[0.23-1.16]$ \\
\hline $30-34$ & $0.13^{* * *}[0.06-0.29]$ & $0.30^{* *}[0.14-0.67]$ \\
\hline $35-39$ & $0.07^{* * *}[0.03-0.14]$ & $0.18^{* * *}[0.08-0.39]$ \\
\hline $40-44$ & $0.03^{* * *}[0.01-0.05]$ & $0.07^{* * *}[0.03-0.17]$ \\
\hline $45-49$ & $0.01 * * * 0.01-0.03]$ & $0.04 * * *[0.02-0.09]$ \\
\hline \multicolumn{3}{|l|}{ Residence } \\
\hline Urban & Ref & Ref \\
\hline Rural & $0.93^{*}[0.84-0.99]$ & $1.24^{*}[1.01-1.53]$ \\
\hline \multicolumn{3}{|l|}{ Occupation } \\
\hline Not working & $1.79 * * *[1.49-2.16]$ & $0.91[0.70-1.17]$ \\
\hline Managerial & $1.72^{* * *}[1.33-2.21]$ & $1.43[0.98-2.10]$ \\
\hline Clerical & $1.89[0.93-3.82]$ & $1.38[0.64-2.10]$ \\
\hline Sales & Ref & Ref \\
\hline Agricultural & $0.88[0.77-1.01]$ & $0.97[0.77-1.22]$ \\
\hline Household & $1.24[0.60-2.54]$ & $1.37[0.65-1.26]$ \\
\hline Manual & $1.20^{*}[1.01-1.43]$ & $1.01[0.81-1.26]$ \\
\hline \multicolumn{3}{|l|}{ Region } \\
\hline Western & $0.89[0.70-1.14]$ & $1.15[0.82-1.60]$ \\
\hline Central & $0.80[0.63-1.01]$ & $1.10[0.79-1.53]$ \\
\hline Greater Accra & Ref & Ref \\
\hline Volta & $0.65^{* *}[0.51-0.84]$ & $0.84[0.58-1.22]$ \\
\hline Eastern & $0.72^{* *}[0.56-0.91]$ & $1.03[0.74-1.45]$ \\
\hline Ashanti & $0.95[0.74-1.20]$ & $1.57^{* *}[1.13-2.19]$ \\
\hline Brong Ahafo & $1.10[0.86-1.40]$ & $1.47^{*}[1.04-2.08]$ \\
\hline Northern & $2.74^{* * *}[2.14-3.52]$ & $4.03^{* * *}[2.69-6.04]$ \\
\hline Upper East & $1.49 * *[1.17-1.91]$ & $1.63^{*}[1.08-2.47]$ \\
\hline Upper West & $1.45^{* *}[1.11-1.88]$ & $1.90^{* *}[1.24-2.92]$ \\
\hline \multicolumn{3}{|l|}{ Ethnicity } \\
\hline Akan & Ref & Ref \\
\hline
\end{tabular}


Table 2 (continued)

\begin{tabular}{|c|c|c|}
\hline Variables & $\begin{array}{l}\text { Model } 1 \\
\text { cOR } 95 \% \mathrm{Cl}\end{array}$ & $\begin{array}{l}\text { Model } 2 \\
\text { aOR } 95 \% \mathrm{Cl}\end{array}$ \\
\hline Ga-Adangbe/Ewe & $0.86[0.74-1.01]$ & $1.04[0.81-1.33]$ \\
\hline Mole-Dagbani & $1.97^{* * *}[1.71-2.28]$ & $1.45 *[1.07-1.97]$ \\
\hline Others & $2.25^{* * *}[1.92-2.64]$ & $1.78^{* * *}[1.35-2.35]$ \\
\hline \multicolumn{3}{|l|}{ Parity } \\
\hline $0-3$ births & $9.08^{* * *}[8.01-10.30]$ & $7.15^{* * *}[5.97-8.58]$ \\
\hline Four or more births & Ref & Ref \\
\hline \multicolumn{3}{|l|}{ Religion } \\
\hline Christianity & Ref & Ref \\
\hline Islam & $2.17^{* * *}[1.87-2.52]$ & $1.87^{* * *}[1.49-2.34]$ \\
\hline Traditionalist & $1.12[0.82-1.53]$ & $1.40[0.92-2.12]$ \\
\hline No religion & $1.05[0.78-1.41]$ & $1.55^{*}[1.06-2.27]$ \\
\hline \multicolumn{3}{|c|}{ Frequency of reading newspaper/magazine } \\
\hline Not at all & $0.68^{* *}[0.53-0.89$ & $0.91[0.65-1.27]$ \\
\hline Less than a week & $0.87[0.62-1.23]$ & $0.93[0.62-1.40]$ \\
\hline At least once a week & Ref & Ref \\
\hline \multicolumn{3}{|c|}{ Frequency of listening to radio } \\
\hline Not at all & $0.95[0.81-1.01]$ & $0.95[0.76-1.18]$ \\
\hline Less than a week & $0.86^{*}[0.76-0.97]$ & $0.91[0.77-1.08]$ \\
\hline At least once a week & Ref & Ref \\
\hline \multicolumn{3}{|c|}{ Frequency of watching television } \\
\hline Not at all & $0.74^{* * *}[0.66-0.84]$ & $0.76^{*}[0.61-0.95]$ \\
\hline Less than once a week & $0.87[0.75-1.00]$ & $1.14[0.93-1.39]$ \\
\hline At least once a week & Ref & Ref \\
\hline N & 5389 & 5389 \\
\hline Pseudo $R^{2}$ & & 0.34 \\
\hline
\end{tabular}

Exponentiated coefficients; $95 \%$ confidence intervals in brackets

$c O R$ crude odds ratio, $a O R$ adjusted odds ratio

${ }^{*} p<0.05,{ }^{* *} p<0.01,{ }^{* * *} p<0.001$

least once a week (66.1\%), those who listened to radio at least once a week (59.3\%) and those who watched television at least once a week (60.8\%).

Model 1 of Table 2 shows results of the unadjusted odds ratios of the socio-economic and demographic predictors of desire for more children. All the variables showed statistically significant associations with desire for more children at the crude level. The second model of Table 2 presents results of the multivariable logistic regression analysis of the socio-economic and demographic predictors of fertility preferences among women of reproductive age in Ghana, while controlling potential covariates. The results indicate that women with no formal education were more likely to desire for more children compared to those with higher level of education $(\mathrm{aOR}=2.16,95 \%$ CI 1.29-3.48). Desire for more children was less among women aged 45-49 compared to those aged 15-19 (aOR $=0.04,95 \%$ CI 0.02-009). The odds of desire for more children was higher among women who lived in rural areas compared to those who lived in urban areas $(\mathrm{aOR}=1.24,95 \% \mathrm{CI} 1.01-1.53)$. With region, women who lived in the Northern region were more likely to desire for more children compared to those who lived in the Ashanti region $(\mathrm{aOR}=4.03,95 \%$ CI 2.69-6.04). Similarly, women who belonged to other ethnic groups were more likely to desire for more children compared to Akans ( $\mathrm{aOR}=1.78,95 \% \mathrm{CI} 1.35-2.35)$. The desire for more children was higher among women with $0-3$ births compared to those with four or more births (aOR $=7.15,95 \%$ CI 5.97-8.58). In terms of religion, Muslim women were more likely to desire for more children compared to Christians ( $\mathrm{aOR}=1.87,95 \% \mathrm{CI}$ 1.49-2.34). Women who never watched television were less likely to desire for more children compared to those watched television at least once a week $(\mathrm{aOR}=0.76,95 \%$ CI 0.61-0.95). 


\section{Discussion}

This study sought to assess the association between socio-economic and demographic factors and fertility preferences among women of reproductive age in Ghana. The results from the study showed that women in the richest wealth quintile and those with higher level of education are less likely to desire more children. These findings are in line with previous studies that higher socio-economic status is associated with lower fertility desires. Specifically, similar findings have been observed in Nigeria [25], India [26] and various multi-country studies [27-30]. However, our results deviate from what was found in a Ugandan study by Matovu et al. [31]. They found that, those in lower socio-economic status (education), thus having primary education were associated with higher fertility desire than those with no formal education. The possible reasons for the variation in study findings could be differences in cultural believes, levels of socio-economic development and the importance ascribed to children in the various settings. Nonetheless, Matovu et al. [31] suggested a qualitative study to unravel such nuances. This therefore implies that women with low level of education should be educated on the importance associated with low fertility.

The current findings on the association between socio-economic status and fertility preferences can be discussed within the context of the wealth flow hypotheses postulated by Caldwell $[16,17]$. The theory explains that in modern societies those who are in high socioeconomic strata tend to interpret more children as additional burden which can strain their resources including time as opposed to those in the low socio-economic status who wish to have more children with the notion that the children will serve as their old age security. In addition, due to the various economic activities of those in high socio-economic activities, they might not have more children as opposed to those who are in the low socio-economic status. Another plausible explanation by Channon and Harper [32] is that in contemporary era, women have competing life goals. They maintained that for highly educated women, it is sometimes problematic for them to combine many children and life goals such as occupying certain managerial position that will not allow certain amount of maternity leave within a given period.

Aside the socio-economic factors, it is worthwhile to discuss the association found among the demographic factors and desire for more children. The study showed that as parity increased, the less likely it is for women to indicate that they want more children. This is congruent with several previous studies in other parts of the world such as Nigeria [33, 34], China [35] and Sri Lanka [36]. The probable explanation to this finding is that some of these women might have achieved their desired number of children.

Our study also showed a statistically significant association between region of residence, ethnicity, religious affiliation and fertility desires. Specifically, those in the northern part of Ghana (Northern and Upper West), those who belonged to the Mole-Dagbani ethnic group and those who are Muslims tend to have higher odds of desiring more children. Several studies have been conducted on the socio-cultural beliefs and practices surrounding fertility behaviour in Ghana [37]. In Ghana, the northern part is predominantly occupied by the Mole Dagbani's of whom majority are also Muslims. In terms of religion some scholars have explained that stronger religious beliefs tend to correlate positively with a stronger desire more children [38, 39]. A recent qualitative study conducted by Abdi et al. [40] in two Muslim communities in Kenya found that Muslim women tend to desire more children due to the belief that children are a blessing from God. Due to this some of them would wish to receive more of the blessings God has in stock for them in the form of children. Another possible explanation is that some Muslim women who are in polygamous marriages tend to compete in terms of the number of children to ensure the continuity of their husband's lineage and to enhance their own bargaining power and 'value' in the relationship [41]. The patriarchal nature of the northern societies and the various ethnic groups places so much credence on large family sizes [37] which might influence the women's' views on desire for more children. This therefore suggest the need for more education targeting various community leaders, family heads and husbands to appreciate the importance of smaller family sizes by adopting various contraceptives. These can be achieved through education during community durbars and other social gatherings.

\section{Strengths and limitations}

This study derives its strength from the use of nationally representative dataset that employed multi-stage sampling technique to select the respondents. With this, the findings are generalisable to all women in their reproductive age in Ghana to a greater extent. The relatively large sample size also aided in fitting robust logistic regression models to model the association between socio-economic status and desire for more children while controlling for confounders. Despite these strengths, the study's results must be interpreted cautiously against the following limitations. First, it is impossible to establish temporality of sequence. Second, the possibility of social desirability biases cannot be overruled. 


\section{Conclusion}

This study concludes that women in high-socio economic status are less likely to desire for more children. On the other hand, women in the Northern, Upper East and those belonging to the Islamic religious sect tend to desire more children. To aid in fertility control programmes deigning and strengthening existing ones, these factors ought to be critically considered. It is crucial to educate those with low level of education on the importance of attaining fewer children by adopting various family planning strategies including contraceptive usage.

\begin{abstract}
Abbreviations
ANC: Antenatal care; DHS: Demographic and Health Surveys; cOR: Crude odds ratios; aOR: Adjusted odds ratio; Cl: Confidence interval; GHS: Ghana Health Service; GDHS: Ghana Demographic and Health Survey; WHO: World Health Organization; ICF: Inner City Fund; USAID: United States Agency for International Development; UNDP: United Nations Development Programme; GAC: Ghana AIDS Commission; PCA: Principal Component Analysis.
\end{abstract}

\section{Acknowledgements}

The authors thank the MEASURE DHS project for their support and for free access to the original data.

\section{Authors' contributions}

BOA conceived the study. BOA, AS, EKA, EKA, EB and SY designed the study and drafted the initial manuscript. AS had final responsibility to submit for publication. All authors read and approved the final manuscript.

\section{Funding}

The authors have no support or funding to report.

\section{Availability of data and materials}

Data for this study were sourced from Demographic and Health surveys (DHS) and available here: http://dhsprogram.com/data/available-datasets.cfm.

\section{Ethics approval and consent to participate}

The survey was ethically approved by the ICF International and Ethical Review Committee of Ghana Health Service [10]. We did not need ethical permission for this study since the DHS datasets are publicly accessible. All ethical procedures were, however, observed during to survey to align the study with the regulations for the protection of human rights as required by the U.S. Department of Health and Human Services. More details regarding DHS data and ethical standards are available at: http://goo.gl/ny8T6X.

\section{Consent for publication}

No consent to publish was needed for this study as we did not use any details, images or videos related to individual participants. In addition, data used is available in the public domain.

\section{Competing interests}

Sanni Yaya is Editor-in-Chief of this journal.

\section{Author details}

${ }^{1}$ School of Public Health, Faculty of Health, University of Technology Sydney, Sydney, Australia. ${ }^{2}$ Department of Population and Health, University of Cape Coast, Cape Coast, Ghana. ${ }^{3}$ College of Public Health, Medical and Veterinary Sciences, James Cook University, Townsville, QLD, Australia. ${ }^{4}$ School of International Development and Global Studies, University of Ottawa, Ottawa, Canada. ${ }^{5}$ The George Institute for Global Health, The University of Oxford, Oxford, UK.

Received: 20 April 2020 Accepted: 13 December 2020

Published online: 02 January 2021

\section{References}

1. Arthur JL. Family size and its socio-economic implications in the Sunyani Municipality of the Brong Ahafo Region of Ghana, west Africa. Ghana: Centre for Development Studies, Faculty of Social Science, University of Cape Coast; 2005.

2. Zare Z, Kiaee abar R, Laal Ahangar M. Fertility motivations and its related factors in women of reproductive age attended health centers in Sabzevar, Iran. J Midwifery Reprod Health. 2019;7(1):1544-52.

3. Novignon J, Djossou NG, Enemark U. Childhood mortality, intra-household bargaining power and fertility preferences among women in Ghana. Reprod Health. 2019;16:139.

4. Ashraf $\mathrm{QH}$, Weil $\mathrm{DN}$, Wilde J. The effects of fertility reduction on economic growth. Popul Dev Rev. 2013;39(1):97-130.

5. Azmoude E, Behnam H, Barati-Far S, Kabirian M. The relationship of socio-demographic factors, fertility behavior and child's perceived value with fertility intention of women in a region in the East of Iran. IJCBN. 2017;5(2):123-33.

6. Finaly JE, Norton MK, Mejia-Guevara I. Adolescent fertility and child health: the interaction of maternal age, parity and birth intervals in determining child health outcomes. J Child Health Nutr. 2017;6(1):16-33.

7. Calikoglu EO, Yerli EB, Yilmaz S, Kavuncuoglu D, Kosan Z, Aras A. Fertility preferences of women in a province center. Eurasian J Med. 2018;50(3):187-92.

8. Hong R, Fronczak A, Chinbuah A, Miller-Calverton A. Ghana trend analysis for family planning services, 1993, 1996, and 2002. Maryland: ORC Macro; 2005.

9. Habyarimana F, Ramroop S. The analysis of socio-economic and demographic factors associated with contraceptive use among married women of reproductive age in Rwanda. Open Public Health J. 2018;11:348-59.

10. Ghana Statistical Service (GSS), Ghana Health Service (GHS), ICF International. Ghana Demographic and Health Survey 2014. Rockville: GSS, GHS, and ICF International; 2015.

11. Adhikari R. Demographic, socioeconomic, and cultural factors affecting fertility differentials in Nepal. BMC Pregnancy Childbirth. 2010;10:19.

12. Rai P, Paudel IS, Ghimire A, et al. Effect of gender preference on fertility: cross-sectional study among women of Tharu community from rural area of eastern region of Nepal. Reprod Health. 2014;11:15.

13. Adibi SM, Arjmand SE, Darvishzadeh Z. The investigation of Fertility increase and effective factors on it among the Kord clan in Andimeshk. J Iran Soc Dev Stud. 2012;4:81-98.

14. Black DA, et al. Are children "normal"? Rev Econ Stat. 2013;95(1):21-33.

15. Caplescu R. Using the theory of planned behaviour to study fertility intentions in Romania. Procedia Econ Financ. 2014;10:125-33.

16. Caldwell JC. Mass education as a determinant of the timing of fertility decline. Popul Dev Rev. 1980;6:225-55.

17. Caldwell JC. On net intergenerational wealth flows: an update. Popul Dev Rev. 2005;31(4):721-40.

18. World Bank. World Development indicators. Washington DC: The World Bank Group; 2017.

19. Nyarko P. et al. Infant mortality and the pace of childbearing in Ghana: some evidence of son preference. In: Third African Population Conference, Durban, South Africa, 6-10 December 1999. http://www.popli ne.org/node/527481\#sthash.WAI9YCIE.dpuf. Accessed 3 Aug 2017.

20. Aviisah PA, et al. Modern contraceptive use among women of reproductive age in Ghana: analysis of the 2003-2014 Ghana Demographic and Health Surveys. BMC Women's Health. 2018;18(1):141.

21. Ronsmans C, Graham WJ, Lancet Maternal Survival Series Steering Group. Maternal mortality: who, when, where, and why. The Lancet. 2006;368(9542):1189-200.

22. Joshi $C$, et al. Factors associated with the use and quality of antenatal care in Nepal: a population-based study using the demographic and health survey data. BMC Pregnancy Childbirth. 2014;14(1):94.

23. Amo-Adjei J, et al. Analysis of socioeconomic differences in the quality of antenatal services in low and middle-income countries (LMICS). PLoS ONE. 2018;13(2):e0192513.

24. Inner City Fund (ICF). Demographic and Health Surveys standard recode manual for DHS7, The Demographic and Health Surveys program. Rockville: ICF; 2018. 
25. Akpa OM, Ikpotokin O. Modeling the determinants of fertility among women of childbearing age in Nigeria: analysis using generalized linear modeling approach. Int J Hum Soc Sci. 2012;2(18):106-7.

26. Jiang $L$, Hardee K. Women's education, family planning, or both? Application of multistate demographic projections in India. Int J Popul Res. 2014 (2014).

27. Götmark F, Andersson M. Human fertility in relation to education, economy, religion, contraception, and family planning programs. BMC Public Health. 2020:20(1):1-17.

28. Samir KC, Lutz W. The human core of the shared socioeconomic pathways: population scenarios by age, sex and level of education for all countries to 2100. Glob Environ Change. 2017;42:181-92.

29. Wang $Q$, Sun $X$. The role of socio-political and economic factors in fertility decline: a cross-country analysis. World Dev. 2016;87:360-70.

30. Wolf $\mathrm{K}$, Mulder $\mathrm{CH}$. Comparing the fertility of Ghanaian migrants in Europe with nonmigrants in Ghana. Popul Space Place. 2019;25(2):e2171.

31. Matovu JKB, et al. Determinants of fertility desire among married or cohabiting individuals in Rakai, Uganda: a cross-sectional study. Reprod Health. 2017;14(1):2.

32. Channon MD, Harper S. Educational differentials in the realisation of fertility intentions: is sub-Saharan Africa different? PLoS ONE. 2019;14(7):e0219736.

33. Adebowale SA, Adeoye IA, Palamuleni ME. Contraceptive use among Nigerian women with no fertility intention: interaction amid potential causative factors. Afr Popul Stud. 2013;27(2):127-39.

34. Babalola $S$, et al. Factors affecting the achievement of fertility intentions in urban Nigeria: analysis of longitudinal data. BMC Public Health. 2017;17(1):942
35. Eklund L. Preference or aversion? Exploring fertility desires among China's young urban elite. Intersect Gender Sex Asia Pac. 2016;39:1-16.

36. De Silva WI. Do fertility intentions and behaviour influence sterilization in Sri Lanka? Asia-Pac Popul J. 1992;7(4):41.

37. Bawah AA, Asuming P, Achana SF, Kanmiki EW, Awoonor-Williams JK, Phillips JF. Contraceptive use intentions and unmet need for family planning among reproductive-aged women in the Upper East Region of Ghana. Reprod Health. 2019;16(1):26.

38. Barber JS, Pearce LD, Chaudhury I, Gurung S. Voluntary associations and fertility limitation. Soc Forces. 2002;80(4):1369-401.

39. Wachira EW. Determinants of fertility preferences in Kenya a study based on the 1998 Kenya demographic and health survey data. Doctoral dissertation, University of Nairobi. 2001.

40. Abdi B, et al. "Children are a blessing from God" — a qualitative study exploring the socio-cultural factors influencing contraceptive use in two Muslim communities in Kenya. Reprod Health. 2020;17:1-11.

41. Ganle JK, Dery I. 'What men don't know can hurt women's health': a qualitative study of the barriers to and opportunities for men's involvement in maternal healthcare in Ghana. Reprod Health. 2015;12(1):93.

\section{Publisher's Note}

Springer Nature remains neutral with regard to jurisdictional claims in published maps and institutional affiliations.
Ready to submit your research? Choose BMC and benefit from:

- fast, convenient online submission

- thorough peer review by experienced researchers in your field

- rapid publication on acceptance

- support for research data, including large and complex data types

- gold Open Access which fosters wider collaboration and increased citations

- maximum visibility for your research: over 100M website views per year

At BMC, research is always in progress.

Learn more biomedcentral.com/submissions 